\title{
Discussion of the Digital City Management Information System Construction
}

\author{
CHEN Xue X, a $^{1}$ \\ ${ }^{1}$ School of Management, Wuhan University of Technology, Wuhan 430070, China \\ a ChenXue1031@yeah.net
}

Keywords: Digital; City management system; Construction

\begin{abstract}
Recently, with the complete propulsion of digital development zone construction, the information-based instruments and city informatization level in the city have been improved gradually and obviously. Especially, the successful implementation of engineering project like the basic information resources library, involved e-government network engineering, video monitoring system, geographic information, population, legal persons and so on, has released the stress and risen informatization level of urban management to some extents, which attributes to the establishment of digital city management. At present, the operation of digital city management system demonstrates that digital urban management is regarded as an efficient way to carry out the city management scientifically, strictly, subtly and effectively.
\end{abstract}

\section{Introduction}

Digital city management, the important content of e-government construction, belongs to the component of online governance, which can provide efficient way for the social public anticipating in city management, help to develop democracy politics and offer a platform to improve governance efficiency and public service level. Thus, it must be the significant direction of future digital management development because of the features of advanced informational technology application and innovation of administration model, the target of pursuing precise, agile, effective, all-time and all-position digital management as well as the creative management model combining city management and advanced informational technology.

\section{Business process of digital city management information system}

The process of digital city management information system can be divided into three phases (problems discovering, problems dealing and results assessment) and four links which are information collecting, tasks to send, tasks treatment and checking \& ending the case respectively.

\section{Information collecting}

\section{A. Reports from online supervisors}

Online supervisors are responsible for touring the areas in charge continuously, finding out and reporting the problems on city management. The problems sent to information platform by mobile communication terminal in the form of multimedia information like images, lists, audios and words, and will be obtained by city supervising center and district conducting center respectively at the same time.

\section{B. Real-time video monitoring}

The video information collected from the main monitoring areas by the video camera monitoring instruments, will be sent to the information platform by leased lines and got by the city supervising center and the district conducting center respectively meanwhile.

\section{Reports from the public}

The public is responsible for finding out and reporting the problems on city management by the complaint acceptance system, government portals, website of city's urban-management bureau and information kiosks. The problems sent to information platform in the form of multimedia 
information like images, lists,audio and words, and will be obtained by city supervising center and district conducting center respectively at the same time.

\section{Handing to superiors}

This work belongs to city government leaders, city letters and visits bureau, district government leaders and district letters and visits bureau. The problems sent to information platform through the way of leader agreement and phone records in the form of words, will be obtained by city supervising center and district conducting center respectively at the same time.

\section{Tasks to send}

Tasks will be assigned by the district conducting center based on affiliation of problems, which means that if the problem belongs to online supervisors, it would be sent to online supervisors directly; otherwise if the problem belongs to related associations, it would be sent to the associations by the information platform of special government websites.

\section{Tasks dealing}

According to the missions sent by district conducting center, the related associations and online supervisors should respectively deal with the problems of their owns and be required to record the whole dealing process.

\section{Checking \& ending case}

Based on the results from the information platform, the district conducting center ought to inform of online supervisors to check. After then, online supervisors are supposed to check the results treated by themselves and related associations and send the information to the platform. The district conducting center should compare the checking information and treating information. If they are the same, the case can be ended; otherwise the case will be put into the link of tasks sending again. The whole process should be supervised by city supervised center at any time.

\section{Thinking of digital city management information system}

Taking all factors into consideration, the ideas of the system construction are below:

(1) Multi-tier structures: the bottom is data layer; the middle is business logic layer; the upper is user layer, which is mainly the browser.

(2) Data layer is used to deploy the relationship data library, whose system is favor of Oracle9i mainstream data library used to store various data. As for business logic layer, it is technology like Serverlet、JSP、EJB that deals with system business logic. And the user layer is shown by the browser.

(3) The technical route is based on the B/S structure of J2EE.

(4) The operating system is MS Windows 2003 Server.

(5) The applied server is BEA Web Logic Server.

(6) The relationship data library is BEA Web Logic Server

System technical logic is displayed as Figure 1. 


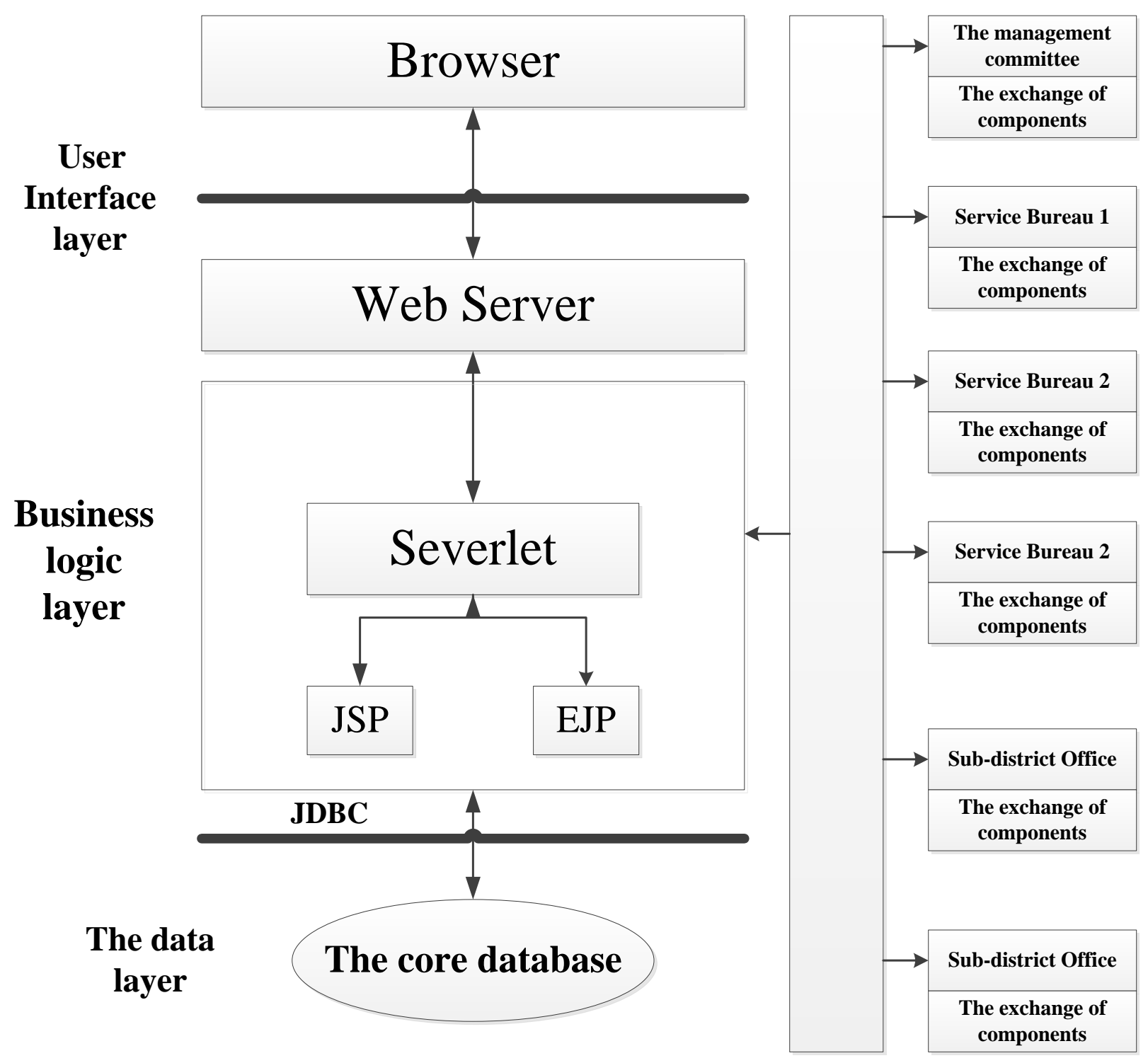

Figure1. System technical logic

The efficient route of using digital city management information system

Clear the leader deployment, features, status and establishment of both supervising center and conducting center as soon as possible

It's mainly about the solution of belongs: make sure of the duty and feature of the two centers, which means that it is necessary to determine the establishment and posts,especially for the management people who need unified names called supervisor \& coordinator, just like the difference of handyman \& employee.

Make related rules as soon as possible

This mission should be carried out at the same with the one above and need to pass the people's congress to clear the duty and features of the two centers. That is to make sure of the management range and features of supervisors. Some related supervising departments and check-up systems are supposed to set up by government.

Improvement of technology in information system

Information locator system should revitalize the whole city for the purpose of solving the problem of signal disturbance. The hardware system ought to be uploaded in order to enlarge RAM, improve video card and handle the problem of slow operating, etc.

Strength the training of supervisors(coordinators), increase salaries and wear uniforms.

Online management is essential for four parts: time management, people management, links 
management and time limitation management. The present management system needs to be enlarged to realize the three shifts for 24 hours a day. Meanwhile, supervisors(coordinators) are required to learn some related knowledge and regulations to improve their basic qualities for the demand for the work. It is necessary to wear uniforms to manage the image of supervisors (coordinators). Wearing uniforms can avoid conflicts for its deterrent effect.

\section{Set up the whole people coordinating regulations}

People can take photos by mobile phone as the evidence and report it. And it is wise to build city management hot line by cell phone. At the moment, there are few cities in China that have open such hot line for the warm-hearted people participating in the urban management.

\section{Conclusion}

The construction of digital city management information system will enhance the government ability of managing and treating, which can monitor the important areas and streets at and time. In this way, social supervising and ruling ability can be enhanced and government service efficiency will be improved. However, digital city management is still a new system. Here, it is stated the analysis research from the proposal of digital city management. It is hopeful to offer a direction for other study in the construction of digital city management, which can decrease loss, reduce costs and improve revenue.

\section{References}

[1] Komninos N. Intelligent cities: innovation, knowledge systems, and digital spaces[M]. Taylor \& Francis, 2002.

[2] Smith T R, Menon S, Star J L, et al. Requirements and principles for the implementation and construction of large-scale geographic information systems[J]. International Journal of Geographical Information System, 1987, 1(1): 13-31.

[3] Jia-yao W. Thinking about E-government and construction of digital cities in china [J][J]. Science of Surveying and Mapping, 2005, 1: 001.

[4] Turban E, Leidner D, McLean E, et al. INFORMATION TECHNOLOGY FOR MANAGEMENT, (With CD)[M]. John Wiley \& Sons, 2008.

[5] Chaolin G U, Manchun L. Discussion on Research" Digital City[J]. URBAN PLANNING REVIEW, 1999, 5: 005. 